\title{
Relationships between Organizational Factors and Political Behaviour Tactics in the Islamic Republic of Iran: Kerman Province
}

\author{
Mohammad Naji ${ }^{1}$, Hamied Taboli ${ }^{2} \&$ Akbar Zolfaghari ${ }^{3}$ \\ ${ }^{1}$ Department of Management, Payame Noor University, PO BOX 19395-3697 Tehran, Iran \\ 2 Department of Management, Payame Noor University, PO BOX 19395-3697 Tehran, Iran \\ ${ }^{3}$ Department of Political Science, Payame Noor University, PO BOX 19395-3697 Tehran, Iran \\ Correspondence: Akbar Zolfaghari, Department of Political Science, Payame Noor University, PO BOX 19395-3697 \\ Tehran, Iran. E-mail: akbar_zolfeghari@yahoo.com
}

Received: February 8, 2012

Accepted: May 2, $2012 \quad$ Published: June 1, 2012

doi:10.5539/ijef.v4n6p108

URL: http://dx.doi.org/10.5539/ijef.v4n6p108

The research is financed by Payame Noor University of Islamic republic of Iran

\begin{abstract}
The organizations try to achieve their goals through using resources such as material and human resources, but most of them are a little successful to achieve their goals, however it is difficult to use the resources in order to achieve to personal and group gains that occur in the organization repeatedly. These actions called as political behavior include activities that go forward in order to work in the people or groups to obtain the protecting the personal gains when there are opposite solutions.

In the present paper, the researcher studies the relationship between the organizational factors and the political behaviors or the policy in the Kerman's governmental organizations. This study to be done by juncture studies and correlative way in the population includes 1992 samples of the Kerman's governmental organizations personnel and classified random sampling that include 322 samples. The researcher uses two questionnaires in order to gather the date and consult with the professors in order for determining the reliability questionnaires and evaluates them through re-examining and finally analyzes the collected data by means of software"SPSS". The results of this study show that there is a relationship between the organizational factors and the personnel's tendency toward the political behavior.
\end{abstract}

Keywords: organization, political behavior, organizational factors and tactics

\section{Introduction}

The political action is the one of the organization's characteristics, because the most organizations employ a lot of people who possess individual characteristics, but the type of the political behavior is very different. However, we accept this fact that the individual differences can play important role in the political scenes, the present evidence and documents verify this fact that some situations and specified cultures cause to develop and comfort special political behavior. (Robbins \& Judge, 2007, p.748). Today world doubtlessly is full of complexes, obscurities, unbelief's and situations that are full of struggles,competitions and interference,the situation of the organizational policies and tactics in these conditions can involve potentially the consequences in the battle field between gains and goals of the organizational different activities and the combination of the coalition authority's process and influence in the organizations internal and external fields exposed to the drastic changes. The goals and gains of the organization's personnel are not in the single file and necessarily they will not conform to each other. It seems that the most of social activists in the organizations at longest head the achievement of goals and their personal gains and utilize the skills and methods of the political behaviors(Monavariyan \& Alikhani, 2001, p. 73).

Up to now, the organizations have observed in the different ways that the most important ways are two principals: the political and the rational ways. According to rational attitude, the organization tries to achieve the explicit and specified goals. When a decision will be made then the goal is determined and the vary solutions are identified then the best solution is choose. But according to political attitude, the organization comprises the coalitions that not agree with the goals. The organizations political pattern consist of groups that possess separate and special their own gain, goals and values. In the organizations, the interference and the disagreement take into account a common task(Nasresfahani, 1997, p. 24) 
Even though, it is impossible to omit practically the political operation within the organization, but the management can decrease its consequences. So the management has a mind when and how they can decrease and utilize it usefully within the organization in order to achieve their goals or the submissiveness of ethical pattern and the political behaviors tactics develop the personals motivation (Ghasemi, 2003, p. 376). The organization is a set of people that their roles is operating the tasks and duties that be assigned. In order to avoid damaging the organization, the political tactics should be put to use so that it develops the clear and friendly relationship between the organization and its personnel's and the organizations resources not to be wasted and the trust not to be decreased.

\section{Methodology}

According to the topic of the study: A Survey of the Relation between the Organizational Factors and the Political Tactics in Kerman's Governmental Organization. The descriptive research is type of the correlation that has been done in this research, since in the descriptive research, variables are be described precisely and completely and in the same way they do. The study is an applied research because of its goal and researcher uses Delfi's different techniques in the different steps of the research. In this study, the sampling way is a cluster sampling, and fit the population size because the number of personnel and organizations is not equal and every organization personnel should be participate in the sampling according to their proportion in the organizations population. So the number of sample is 321 individuals in the present study that they have chosen randomly through the population including 1991 individuals.

Kochran's formulate

$\mathrm{N}=$ population size

$$
\mathrm{n}=\frac{\mathrm{T}^{2} \mathrm{pq} / \mathrm{d}^{2}}{1+1 / \mathrm{N}\left[\mathrm{t}^{2} \mathrm{pq} / \mathrm{d}^{2}-1\right]}
$$

$\mathrm{P}=$ Distribution's percentage of the characteristics.

$\mathrm{Q}=$ Individuals percentage lacking of that characteristics.

$\mathrm{t}=$ Variable size in natural distribution.

$\mathrm{d}=$ Difference between real proportion of the characteristics in the population and the researchers amount of estimation to occur that characteristic in the population.

$$
\begin{gathered}
\mathrm{n}=\frac{(1.96)^{2} \times 0.05 \times 0.5 / 0.05^{2}}{1+1 / 1991\left[(1.96)^{2} \times 0.05 \times 0.5 / 0.05^{2}-1\right]} \\
\mathrm{n}=\frac{384}{1.193}=321
\end{gathered}
$$

\section{Hypothesizes}

1. The second allocation of the sources relates with the political behaviors tactics.

2. The opportunity for promotion in the organization relates with the political behaviors tactics.

3. The low level of trust in the organization relates with the political behaviors tactics.

4. The unclear system of evaluating the personnel's operation the political behaviors tactics.

5. The making democratic decision (group decision) relates with the political behaviors tactics.

6. The unclear rules (lack of tasks explanation) relate with the political behaviors tactics.

7. The intense pressure in order to improve the personnel's operation relates with the political behaviors tactic.

\section{Results}

$\mathrm{Ho}=$ There is not any relationship between the organizational factors and the political behavior tactics.

$\mathrm{H}_{1}=$ There is a relationship between the organizational factors and the political behavior tactics. 
Table 1. Correlation coefficient between the organizational factors and the political behavior

\begin{tabular}{ll}
\hline Significant level tactics & E.S Pearson correlation coefficient \\
\hline 0.001 & 0.195 \\
\hline
\end{tabular}

Table one shows the correlation coefficient between the organizational factors and the political behavior.

According to above table, the amount of the calculated test is significant. It means the amount of sig is less than 0.05, so the null hypothesis is rejected and the alternative hypothesis with reliability of 0.95 percent is accepted. The Pearson correlation coefficient between"the organizational factors and the political behavior tactics is +0.195 with significant level of sig $=0.001$. So there is a relationship between the organizational factors and the political behavior tactics.

Table 2. Brief model for the organizational factors

\begin{tabular}{lllll}
\hline Standard error grade & Adjusted $\mathrm{R}^{2}$ & $\mathrm{R}^{2}$ & $\mathrm{R}$ & Model \\
\hline 8.08764 & 0.035 & 0.038 & 0.195 & 1 \\
\hline
\end{tabular}

Table two shows the brief model for the organizational factors. The Pearson correlation coefficient between these two variable equal +0.195 and coefficient of determination $\left(\mathrm{R}^{2}\right)$ equal 0.035 . On the other hand, the organizational factors explain the 3.5 percent of the political behavior tactics changes.

$\mathrm{Ho}=$ There is not any relationship between the second allocation of resources and the political behavior tactics. $\mathrm{H}_{1}=$ There is a relationship between the second allocation of resources and the political behavior tactics.

Table 3. Correlation coefficient between the second allocation of resources and the political behavior tactics

\begin{tabular}{ll}
\hline Significant level & Pearson correlation coefficient \\
\hline 0.000 & 0.224 \\
\hline
\end{tabular}

Table three shows correlation coefficient between the second allocation of resources and the political behavior tactics. As regard to above table, the amount of the calculated test is significant. It means the amount of sig is less than 0.50 , so the null hypothesis is rejected and the alternative hypothesis is accepted with reliability of 0.95 percent. The Pearson correlation coefficient between the political behavior tactics and the second allocation of the resources is +0.224 and sig $=0.000$. So there is a relationship between the second allocation of resources and the political behavior tactics.

Table 4. Brief model for second allocation of resources

\begin{tabular}{lllll}
\hline Standard error grade & Adjusted $\mathrm{R}^{2}$ & $\mathrm{R}^{2}$ & $\mathrm{R}$ & Model \\
\hline 8.03753 & 0.047 & 0.050 & 0.224 & 1 \\
\hline
\end{tabular}

Table 4 shows the brief model for second allocation of resources. The Pearson correlation coefficient between these two variable equal +0.224 and coefficient of determination $\left(\mathrm{R}^{2}\right)$ equal 0.050 . On the other hand, amount of the second allocation of the resources can explain 4.7 percent of the political behavior tactics changes.

$\mathrm{Ho}=$ There is not any relationship between the promoting in the organization and political behavior tactics.

$\mathrm{H}_{1}=$ There is a relationship between promoting in the organization and political behavior tactics.

Table 5. Correlation coefficient between the opportunity to promote in the organization and political behavior tactics

\begin{tabular}{ll}
\hline Significant level tactics & Correlation coefficient \\
\hline 0.134 & 0.088 \\
\hline
\end{tabular}


Table 5 shows the correlation coefficient between the opportunity to promote in the organization and political behavior tactics. According to above table, the amount of the calculated test is not significant. It means the amount of sig is less than 0.05 , so the null hypothesis is accepted and the alternative hypothesis with reliability of 0.95 percent is rejected. The Pearson correlation coefficient between the behavior tactics and the opportunity to promote in the organization is +0.088 with the significant level of sig $=0.134$. So there is not any relationship between the opportunity to promote in the organization and the political behavior tactics.

$\mathrm{Ho}=$ There is not any relationship between the low level of the trust in the organization and the political behavior tactics.

$\mathrm{H}_{1}=$ There is a relationship between the low level of the trust in the organization and the political behavior tactics.

Table 6. Correlation coefficient between the low level of the trust in the organization and the political behavior

\begin{tabular}{ll}
\hline Significant level tactics & E.S Pearson correlation coefficient \\
\hline 0.002 & 0.184 \\
\hline
\end{tabular}

Table 6 shows the correlation of efficient between the low level of the trust in the organization and the political behaviors. According to above table, the amount of the calculated test is significant. It means the amount of sig is less than 0.05 , so the null hypothesis is rejected and the alternative hypothesis with reliability of 0.95 percent is accepted. The Pearson correlation coefficient between"the low level of the trust in the organization" and the political behavior tactics is +0.184 with significant level of $\mathrm{sig}=0.002$. So there is a relationship between the organizational factors and the political behavior tactics.

Table 7. Brief model for the low trust in the organization

\begin{tabular}{lllll}
\hline Standard error grade & Adjusted $\mathrm{R}^{2}$ & $\mathrm{R}^{2}$ & $\mathrm{R}$ & Model \\
\hline 8.10588 & 0.031 & 0.034 & 0.184 & 1 \\
\hline
\end{tabular}

Table 7 shows the brief model for the low trust in the organization. The Pearson correlation coefficient between these two variable equal +0.184 and coefficient of determination $\left(\mathrm{R}^{2}\right)$ equal 0.034 . On the other hand, the low trust in the organization explains the 3.4 percent of the political behavior tactics changes.

$\mathrm{Ho}=$ There is not any relationship between the undetermined system of evaluating the personnel's operation and the political behavior tactics.

$\mathrm{H}_{1}=$ There is a relationship between the undetermined system of evaluating the personnel's operation and the political behavior tactics.

Table 8. Correlation coefficient between the undetermined system of evaluating the personnel's operation and the political behavior

\begin{tabular}{ll}
\hline Significant level tactics & E.S Pearson correlation coefficient \\
\hline 0.012 & 0.147 \\
\hline
\end{tabular}

Table 8 shows the correlation coefficient between the undetermined system of evaluating the personnel's operation and the political behaviors. According to above table, the amount of the calculated test is significant. It means the amount of sig is less than 0.05 , so the null hypothesis is rejected and the alternative hypothesis with reliability of 0.95 percent is accepted. The Pearson correlation coefficient between"the undetermined system of evaluating the personnel's operation" and the political behavior tactics is +0.147 with significant level of sig $=0.012$. So there is a relationship between the undetermined system of evaluating the personnel's operation and the political behavior tactics.

Table 9. Brief model for the undetermined system of evaluating the personnel's operation

\begin{tabular}{lllll}
\hline Standard error grade & Adjusted $\mathrm{R}^{2}$ & $\mathrm{R}^{2}$ & $\mathrm{R}$ & Model \\
\hline 8.15669 & 0.018 & 0.022 & 0.147 & 1 \\
\hline
\end{tabular}


Table 9 shows the brief model for the undetermined system of evaluating the personnel's operation.The Pearson correlation coefficient between these two variables equal +0.147 and coefficient of determination $\left(\mathrm{R}^{2}\right)$ equal 0.022 . On the other hand, the undetermined system of evaluating the personnel's operation explains the 2.2 percent of the political behavior tactics changes.

$\mathrm{Ho}=$ There is not any relationship between the democratic decisions (group decisions) and the political behavior tactics.

$\mathrm{H}_{1}=$ There is a relationship between the democratic decisions (group decisions) and the political behavior tactics.

Table 10. Correlation coefficient between the democratic decisions (group decisions) and the political behavior

\begin{tabular}{ll}
\hline Significant level tactics & E.S Pearson correlation coefficient \\
\hline 0.016 & 0.140 \\
\hline
\end{tabular}

Table 10 shows the correlation coefficient between the democratic decisions (group decisions) and the political behavior. According to above table, the amount of the calculated test is significant. It means the amount of sig is less than0.05, so the null hypothesis is rejected and the alternative hypothesis with reliability of 0.95 percent is accepted. The Pearson correlation coefficient between" the democratic decisions and the political behavior tactics is +0.140 with significant level of sig $=0.016$. So there is a relationship between the organizational factors and the political behavior tactics.

Table 11. Brief model for the democratic decisions

\begin{tabular}{lllll}
\hline Standard error grade & Adjusted $\mathrm{R}^{2}$ & $\mathrm{R}^{2}$ & $\mathrm{R}$ & Model \\
\hline 8.16524 & 0.016 & 0.020 & 0.140 & 1 \\
\hline
\end{tabular}

Table 11 shows the brief model for the democratic decisions. The Pearson correlation coefficient between these two variables equal +0.140 and coefficient of determination $\left(\mathrm{R}^{2}\right)$ equal 0.020 . On the other hand, the organizational factors explain the 2 percent of the political behavior tactics changes.

$\mathrm{Ho}=$ There is not any relationship between the undetermined roles and the political behavior tactics.

$\mathrm{H}_{1}=$ There is a relationship between the undetermined roles and the political behavior tactics.

Table 12. Correlation coefficient between the undetermined roles and the political behavior

\begin{tabular}{ll}
\hline Significant level tactics & E.S Pearson correlation coefficient \\
\hline 0.022 & 0.133 \\
\hline
\end{tabular}

Table 12 shows the correlation coefficient between the undetermined roles and the political behavior. According to above table, the amount of the calculated test is significant. It means the amount of sig is less than0.05, so the null hypothesis is rejected and the alternative hypothesis with reliability of 0.95 percent is accepted. The Pearson correlation coefficient between" the undetermined roles and the political behavior tactics is +0.133 with significant level of sig $=0.022$. So there is a relationship between the undetermined roles and the political behavior tactics.

Table 13. Brief model for the undetermined roles

\begin{tabular}{lllll}
\hline Standard error grade & Adjusted $\mathrm{R}^{2}$ & $\mathrm{R}^{2}$ & $\mathrm{R}$ & Model \\
\hline 8.17287 & 0.014 & 0.018 & 0.133 & 1 \\
\hline
\end{tabular}

Table 13 shows the brief model for the undetermined roles .The Pearson correlation coefficient between these two variables equal +0.133 and coefficient of determination $\left(\mathrm{R}^{2}\right)$ equal 0.018 . On the other hand, the undetermined roles explain the 1.8 percent of the political behavior tactics changes.

$\mathrm{Ho}=$ There is not any relationship between the intense pressures in order to improve the personnel's operation and the political behavior tactics. 
$\mathrm{H}_{1}=$ There is a relationship between the intense pressures in order to improve the personnel's operation and the political behavior tactics.

Table 14. Correlation coefficient between the intense pressures in order to improve the personnel's operation and the political behavior

\begin{tabular}{ll}
\hline Significant level tactics & E.S Pearson correlation coefficient \\
\hline 0.085 & 1.101 \\
\hline
\end{tabular}

Table 14 shows the correlation coefficient between the intense pressures in order to improve the personnel's operation and the political behavior. According to above table, the amount of the calculated test is not significant. It means the amount of sig is more than 0.05 , so the null hypothesis is accepted and the alternative hypothesis with reliability of 0.95 percent is rejected. The Pearson correlation coefficient between"the intense pressures in order to improve the personnel's operation" and the political behavior tactics is +1.101 with significant level of sig $=0.085$. So there is not any relationship between the intense pressures in order to improve the personnel's operation and the political behavior tactics.

\section{Discussion}

In the recant century's world, the bases of the political behaviors differ from the real term"policy" and the purpose of the most political behaviors not related to the political bases and they only follow the economic or cultural purposes(Naji \& Tabouli, 2010, p. 52). The individual and group political behaviors consisting of their efforts for influencing the others behavior and the course of the organizations events that accomplish for protecting the gains, to supply the needs and progress the goals. According this, all the types of behaviors usually can be considered as a political task. To label a behavior as a political movement entail a judgmental concept. It means that the individuals or groups accomplish this when they want to obtain something and get the points from the others, groups or organization, on the other hand the people often are self-centered in relation to label the behaviors operation by the others and represent it in political and believe that their political behavior is defensible. So they consider this behaviors as defending their rights and legal and lawful gains, while they construe this same behavior as a playing politics when is done by others. Doll, one of the political theorists, believes that the political behavior result from the conflicting intentions and ha says:" if an individual involve the other one in confliction and deprivation in order to seek his goals, the first store of the political behavior has been developed. The confliction and the policy are inseparable twist (Fakhimi, 2003, p. 140). The political behavior is an instrument by which the individuals try to achieve and apply the authority. In an easy sense, the individual's purpose of applying such behavior is finding out the exclusive way(Moorhead \& Griffin, 2008, p. 394). There are a lot of definitions of the political behavior that some definitions are considered as follow:

Mayes and Allen: the political behavior includes having influence on the others through the legal methods to option the legal and legitimate results. Quinn: the political behavior consisting the activities that are applied mostly for increasing the legal power or the individual authority of the groups. Moghimi notify that: the political behaviors are the optional and impulsive influence of the individuals or groups in the opposite situation for increasing or protecting their own gains (Moghimi, 2006, p. 410). The political behavior in the organization consists of the operations that are considered just as the obligations of the individual's official role in the organization. But it influences on allocating the gains and losses within the organization. This definition includes the key elements that cover what the individuals often consider as the organizational policies (Robbins \& Barnwell, 1998, p. 302). The tactics of the organizational policy that are to control the availability to information, to reinforce an ideal effect, to develop a backer base, to criticize the others to present oneself through authorities, to satisfy try to the others and to confederate the powerful allies and to arrange ethical obligations. Some of the political behaviors are naturally moral such as to utilize the legal instrument to increase power and authority, but some others are amoral (Durbin, 2003 , p. 1). They are pointed to be cruel, to cans schism and govern, to keep away competitors and to be Effective factors on the political behaviors. The effective factors on the formation of the political behaviors can be divided into two groups: individual and organizational. The effective factors on the formation of the political behaviors are shown in Figure 1(Note 1).

\section{Conclusion and Recommendations}

The political behaviors can't be removed in the organization the manager who expects that nobody begin the political behavior. Seem to be naive, but the organizational maneuvers can be controlled. Abraham Zaleznik, the Harvard university a professor states"the people can focus on a number of special thing, so the more they focus on 
the political behavior, the less rational and inspirational energy is remind in order to operate the real problems(Naji, 2010, p. 174). Therefore, the practical recommendations to manage the political include:

\subsection{Reduce Uncertainty in the System}

(1). Clarify the bases in the

(2). Differentiate the weak or great operation in paying bonus

(3). Make sure that the bonuses directly relate of the operation

\subsubsection{Competition Reduction}

(1). Try to reach a minimum in the competition between managers in order to obtain the resources.

(2). Try to substitute the long-term or short-term goals of supplying the resources the outside of the organization for obtain the resources.

\subsubsection{To Break the Extant Political Band}

(1). The powerful and stable emperors can be broken by means of removing or dividing the inefficient small groups.

(2). If you are executive manager, be sensitive to managers who their career is to gain the political supports first, warn these people that they must stop the political maneuvers, otherwise dismiss them and it is better to discharge them from the organization.

\subsubsection{To Prevent Forming the Future Political Band}

The political attitude that the organizational goals take priority over the individual power should be considered as the most important indicator of promoting the managers.

\subsubsection{To Have Clear Communications}

The clear communications is one of the very effective techniques in limiting the political behavior, so the existence of these communications prevent that everyone can control the communications and communicative lives.

\subsection{To Study the Causes and Techniques of the Political Behaviors}

Finally if manager knows the causes and techniques of political behavior, he can investigate its effects and controls the decision parameters and in supervisor's point of view, has the suitable knowledge to limit its effects. Generally, the keys for ruhning the political behavior include: If a manager wants to be qualified politically and present the effective political behaviors, he should take some actions. If a manager wants to be qualified politically and present the effective political behavior, he should do a series of actions. Arrange departments around the organizational goals are important to present proper image of organization, to have control over the organizational resources, to be considered as a precious pearl, to be known and to avoid of corrupt people

\subsection{Organizational Factors}

\subsubsection{Uncertainty and Obscurity}

There is a high probability that the political behavior. Found in the environment in which no clear policy to be existed. As operating the organizational actions, the clear and prices law and rules reduce the probability of abusing the power. Uncertainty is an imperative condition for appearing the political behavior

\subsubsection{Different and Contrary Preferences}

The contrary preferences develop when the uncertainty is appeared in the most proper function.

\subsubsection{Distributed Authorities}

Whenever, all the groups which involved in the organization are possessed authority.

\subsubsection{Organization's upward Levels}

In the upward levels of the organization, the political behavior is more than the downward levels.

\subsubsection{Less Trust}

The less the trust, the more the political behavior intensify.

\subsubsection{Win or Lose Culture or Zero Gathering Game}

The more the organization emphasize on the win or lose culture, the more the personnel's motivation will be. If it is supposed that one party achieves to the goal by means of the other one's cost and the nature of this goal should be in a way that none of them can achieve to the goal that called zero gathering game 


\section{References}

Durbin, A. J. (2003). Charismatic and Transformational Leadership.

Fakhimi, F. (2003). Organization Behaviour Management, 1, Tehran: Hastan.

Ghasemi, B. (2003). Organizational Behaviour Theory, 1, Tehran: Hayat.

Moghimi, M. (2006). Organization and Research Approach Management, 5, Tehran: Termeh.

Monavariyan, A., \& Alikhani, F. (2001). Conflict and Political Behaviour Management. Governmental Management, $51(1)$.

Moorhead, G., \& Griffin, R. W. (2008). Organizational Behavior Managing People and Organizations. Dreamtech Press.

Naji, M. (2010). Management and Cultural Development. International Journal of Business and Management, 5(11), 171.

Naji, M., \& Tabouli, H. (2010). Conflict Rate and Job Satisfaction among Staffs in the Islamic Republic of Iran: Rafsanjan Township as a Case Study. Asian Culture and History, 3(2), 49.

Nasresfahani, A. (1997). Political Behaviour in Organization. Tadbir, 75(1).

Robbins, S. P., \& Barnwell, N. (1998). Organization theory: Concepts and cases. Prentice-Hall, Sydney.

Robbins, S. P., \& Judge, T. (2007). Organizational behavior, 11. Prentice Hall.

Notes

Note1. Figure 1 shows the effective factors on the formation of the political behaviors

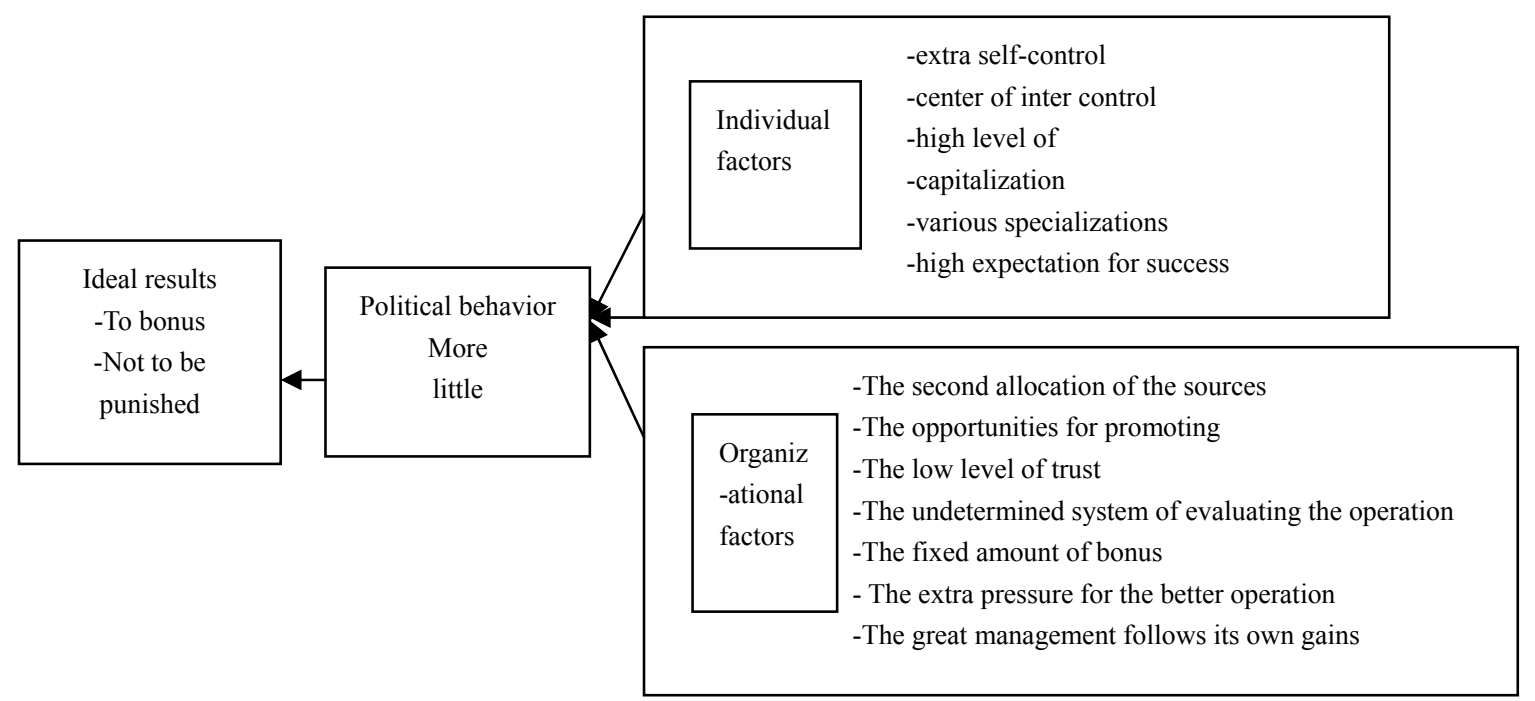

(Robbins \& Judge, 2007, p. 474)

Figure 1. 